\title{
Improv: Transforming Physicians and Medicine
}

\author{
Ankit Mehta $^{1,2} \cdot$ Belinda Fu $^{3,4,5} \cdot$ Erica $\mathrm{Chou}^{6} \cdot$ Suzanne Mitchell ${ }^{7}$ David Fessell $^{8}$
}

Accepted: 20 November 2020 / Published online: 1 December 2020

(C) International Association of Medical Science Educators 2020

\section{Introduction}

Human connection is central to the practice of medicine. Interpersonal communication, collaboration, and adaptability are critical skills for a medical professional. This is the hidden curriculum in the medical education. Medical improv is an exciting new training approach and can help address this important aspect of medical education.

Medical improv is the adaptation of improvisational theater principles and exercises to enhance skills including communication, teamwork, and cognition [1]. Medical improv training teaches powerful tools that can enable providers to more easily and deeply connect with patients. These tools include attentive listening, observation, emotional presence, empathy, collaboration, and respect for multiple viewpoints [1-5]. Another strength of medical improv is its potential to increase clinicians' comfort level and skills with uncertainty, ambiguity, and surprise which are ubiquitous in medical practice [3-5].

The tenets of improv (e.g., be fully present, authentically vulnerable, willing to take risks, and play as part of a team) turn out to be some of the prime ingredients of growing into wholeness as a human being. Clinicians around the world are learning medical improv because of its potential to transform lives through the cultivation of essential skills and values [3-5].

Ankit Mehta

drmehtaankit@gmail.com

1 Internal Medicine, HealthPartners, St. Paul, MN, USA

2 Minneapolis, USA

3 Mayutica Institute, Seattle, WA, USA

4 Family Medicine, Swedish Family Medicine Residency - First Hill, Seattle, WA, USA

5 University of Washington, Seattle, WA, USA

6 Pediatrics, Medical College of Wisconsin, Milwaukee, WI, USA

7 Family Medicine/Palliative Care, Boston University School of Medicine, Boston, MA, USA

8 Radiology, University of Michigan, Ann Arbor, MI, USA
Each report below is a first-hand account of the transformational power of improv, written by physicians practicing internal medicine, pediatrics, family medicine, palliative care, and radiology in cities across the country.

\section{Improv Magic}

Picture a newly minted academic faculty, profoundly anxious to give a resident teaching conference. He practices in the empty conference room the night before. When teaching the next day, his eye contact is primarily with the "eye" of the slide projector. A colleague offers penetratingly accurate feedback - his awkwardness and anxiety definitely show. It's not just a private torture [6].

This was me, and it seems like a lifetime ago. At the urging of a friend, I tried an 8-week improv course. Almost instantly I knew this was the medicine I needed. The 8-week course stretched into another and another ... and before long it was two years and the entire Second City Detroit conservatory program. Along the way I discovered a growing confidence and comfort on stage, a visceral experience of shifting the nauseous anxiety into an almost addictive kind of excitement. Miracle of miracles - it can be fun to be on stage!

When an opportunity arose to teach improv skills to medical students, I replied with one of the fundamental tenets of improv: "Yes, and ..." "Yes" means to accept or affirm what is offered to you by others; "and" means to contribute something new that builds upon that offer [6]. It has been a gift and a great joy to share a "secret" of my private life - a truly transformational part-with the next generation of doctors [2].

—David Fessell, M.D., Radiology, University of Michigan

\section{Yes, and...}

The fundamental principle of improv, "Yes, and ...," has been a challenge for me to embrace. It's not in my nature to simply 
say "Yes" whenever a suggestion is made; rather, my first instinct is to logically think through everything and find potential flaws. Improv invited me to change the way I approach my interactions with others. In improv theater, the worst possible thing to do is to deny, as refusing a "gift" effectively ends the scene. At first, I felt a lot of internal conflict about going along with other people's suggestions when I had something different in mind. But then I saw the way "Yes, and" moves a scene forward, and how my improv partners responded when what they said was accepted, and so I became a believer of the power of "Yes, and."

Outside of the improv classroom, I've continued to utilize "Yes, and" in both my professional and personal lives. As I talk with patients and families who have different views on vaccinations or antibiotic treatments, I've found that the discussions are better when, even if I don't agree, I can affirm their truths [6]. In current clinical learning environments, I've seen medical students engage so much better when their questions and thoughts are affirmed instead of denied. I have found "Yes, and" to be so effective that I now use it when talking with my toddler. Happily, the number of screaming tantrums has dropped because she, too, appreciates affirmation. I'm thankful for "Yes, and..." as it continues to transform my life.

—Erica Chou, M.D., Pediatrics, Children's Hospital of Wisconsin

\section{Reflections in the Mirror}

"Next, we'll do an exercise in pairs called Mirror," says the improv instructor leading our class. I turn and face the person to my right. She looks at me seriously. The instructor says, "Decide who will lead and who will follow. For one minute, followers will mirror the movements of the leaders. Go!" We begin without words. My partner leads and I follow. The power shifts between us. As follower, I struggle to synchronously mirror her gestures. I miscalculate my partner's shifting movements, clumsily recover, and try harder. Finally, we stop.

The instructor debriefs the group: "What was that like?"

"It was hard ... for both of us! Why?"

The group agrees that we neglected the needs of our partners - focusing on the task rather than communicating with one another.

"Try again. And change roles."

Now, I am leader. I move more slowly. I offer subtle cues indicating I will change movements. I make eye contact. We synchronize! We feel the joy of success. High Five!
I reflect, realizing that in ten minutes of immersive play I experienced the power of empathy, learned effective team communication, and explored the frustration of mistakes. Improv makes the power of empathy visible. It helps me appreciate mistakes, foster self-compassion, and learn quickly how my behaviors affect others.

-Suzanne Mitchell, M.D., M.Sc., Family Medicine/

Palliative Care, Boston University School of Medicine

\section{Take a Bow}

"You need to be more on time. It's affecting the team."

My program director was giving me feedback. As he speaks my shoulders curl inward like I'm ready for a fight; I duck my head, my brain swirls with excuses; under the desk, I clench my fists. I am ready to deny, deflect, or flee — anything to avoid confronting my mistake.

Suddenly a voice flashes through my mind: "Ta-da!"

It is the voice of improv.

Flaws are not tolerated in medicine. Though we appropriately strive for the highest standards of patient care, we inappropriately extrapolate that effort into an unforgiving intolerance for human imperfection, cultivating a culture of shame [6]. For much of my life, I felt I was unworthy of existing in this "perfect" world; "imposter syndrome" pervaded every aspect of my life. Knowing I was far from perfect, I attempted to hide or diminish any mistake, big or small. I became convinced that if anyone discovered I was flawed, I would lose my job, my accolades, even my friendships.

But in improv, flaws are gifts. Years ago, when I made my first mistake in an improv class, I wished I could disappear, but instead the instructor cheered, "Ta-da!" I looked at him, confused. "Celebrate failure," he explained. "Embrace the errors, the unexpected. That's where creativity and resilience lie. Every time you make a mistake, throw your hands up in the air, like a circus performer, say "Ta-da!" and take a huge bow! Let us know you're okay, because every mistake is an opportunity to grow." [7]. And so I straightened my shoulders, stood up tall, and took a bow. My classmates cheered, and I smiled.

I've since taken a million failure bows, on-stage and off, as I integrate this philosophy of humility and kindness into my life. I no longer anxiously hide every mistake, I don't pretend to know all the answers, I forgive myself when I fail, and I support others when they falter. I have learned to celebrate imperfections as opportunities for growth, instead of causes for shame [8]. 
Beneath the desk, I unclench my hands. I straightened my shoulders and sit up tall. I look my director in the eye, and with a smile, say "Thank you."

—Belinda Fu, M.D., Family Medicine, Swedish Family Medicine Residency - First Hill/University of Washington

\section{Artist at Work}

I was meeting with Mary's daughter, Laura. With her progressive and worsening dementia, Mary was caught in an endless misery of recurrent hospital admissions due to pneumonia, UTI, heart failure, and many other ailments. Providing aggressive medical care seemed futile at best.

After initial courtesies, we sat down. I expressed my concerns in plain, honest terms: Let's clarify goals, make Mary's care comfort-focused, and not pursue aggressive, futile measures. Laura erupted in anger and insults. She called me "uncaring," and much more. She concluded with a pointed accusation that hung in the air: "So you are asking me to kill my mother?"

I was speechless. The room felt claustrophobic. I wanted to flee. This was not the way I expected this conversation to go.

Desperate, I reached for my improv tool kit. Listen. Pay attention to verbal and non-verbal communication. Read her emotion. Cope with ambiguity. Pay attention to her cues. Stay open.

I stayed with her. I noticed her arched eyebrows, flaring nostrils, and raised voice- a strong emotional cue. She doesn't need more information, I realized. What she needed from me was to unequivocally acknowledge her emotion.

I lowered my voice and replied, "This seems hard; I can only imagine." I complimented her for her mother's care and advocacy. She let out a sigh. "It has been hard." Her shoulders stooped, her head dropped, and she sunk in the chair. Silence hung for a several seconds.

When she spoke next, her voice quivered. Her sharp rage had turned to a deeper grief. She shared that her mother was a remarkable woman - a single parent who managed to complete her education, support her family, and be a role model for them. Her mother volunteered at homeless youth shelters and always said, "If you save one life, you save the whole world."

I was let into a broader, beautiful canvas of Mary's world. As her daughter spoke, I could see her pride and love, and the torment of seeing her mother reduced to dependence on others for the most basic human needs. I saw Laura's vulnerability, and her desperate desire to not fail her mother. She, in turn, saw me as a caring ally.

I keep reaching for my improv tool kit; it seems deeper and richer the more I use it.

—Ankit Mehta, M.D., FHM, FACP, Hospitalist, HealthPartners, St. Paul, MN

\section{Discussion}

Medical improv is a growing movement in medical education. Improv is both an art form and a skill set, both a performance and a practice. Listening, observing, and responding in the moment deepen the human capacity to be present. This is how improv fosters meaningful connections; it's the secret of its transformative power.

Traditionally, improvisational theater is a form in which a play or scene is produced spontaneously by the actors. Improvisers hone their skills and develop the ability to listen closely, focus, accept others' ideas and support one another through practice. Medical improv does not train participants to be actors, but rather teaches them to effectively and spontaneously react to situations and interact with others in the clinical environment. Every clinical encounter prompts a clinician to quickly assess and connect with a new "scene partner." Medical improv can help foster sophisticated skills in collaborative narrative building.

Medical improv training requires time and concerted efforts; it has the potential to provide a rich and effective skill set. Our hope from this compendium of personal reports is for readers to gain knowledge of how core improv principles can apply in their practice.

In the essay "Improv Magic," David Fessell, a radiologist, emphasizes that physicians and improvisers must develop the mental agility to think creatively, cope with ambiguity and recognize patterns in rapidly changing circumstances, all the while maintaining professional composure under great stress. Improvisational training teaches its practitioners to accept uncertainty and ambiguity as the conditions in which you must perform, rather than reflexively trying to impose order on something that has not yet unfolded $[3,4,9]$. This essay also introduces the idea of "Yes, and"- - a fundamental principle of improv.

In her essay "Yes, and" Erica Chou, a pediatrician applies this concept to the clinical context as an opportunity to learn from the patient's communication and build upon it. "Yes, and" doesn't imply indiscriminate acquiescence or capitulation to all demands of patients but rather a "yes" to understanding their view "and" ways to connect as we find a common ground.

"Reflections in the mirror," by Suzanne Mitchell, a family medicine and palliative care physician, is a reminder that improvisation, much like medicine, is a team sport. A core tenet of improv is to "make your scene partner look good" [10]. For an improviser, all individuals are "scene partners." In clinical context, it encourages physicians to recognize patients and care team members as equal partners. It discourages egocentered mindset that hinders collaboration. The mirror exercise shows how quickly a simple activity uncovers truth in people who are willing to see it and reinforces to learn how one's behavior can affect others. 
The essay "Take a Bow" by Belinda Fu, also a family medicine physician, illustrates the powerful principle in improvisation, there are no mistakes, only gifts. It is a liberating mindset, that helps one recognize everything as a gift. In clinical context, looking for "gifts" can allow clinicians to reframe errors and mistakes as opportunities to grow and provide. This tenet can encourage physicians to practice mindfulness with both patients and team members. This is a radical departure in how we shape and train our learners - where mistakes are to be avoided at all costs and perfection is aspirational. While educators teach professionalism, our mistakes have the power to subsume us. Selfcompassion has been defined as being composed of mindfulness, kindness toward self, and recognition of one's common humanity with others [11]. Teaching our learners to turn the shame of mistakes into accepting our very human flaws, owning the issues, and moving forward is a much-needed value conveyed by improv training.

The final essay "Artist at Work" by Ankit Mehta, an internal medicine physician demonstrates how embracing improv principles can shift an intense encounter - one of the ubiquitous crucial conversations clinicians navigate throughout their career. In an uncomfortable, uncertain situation, reaching for his "improv tool kit" enabled a caring clinician to stay present as he shifted his focus from conveying information to connecting with emotion.

The experiences reflected in these essays emphasize how improv can cultivate a "letting go of self" and embracing the vulnerability of "yes, and." They demonstrate the power of active listening: learning when to speak and when to listen. They reminds us of the critical role of empathy in relationships and how it can help navigate even the most intense conversations [2, 12-14]. Above all, they emphasize presence- the purposeful practice of awareness, focus, and attention with the intent to understand and connect with others $[15,16]$. In an increasingly fragmented world, improv training fosters a mindset of presence and deep connection with self and others.

\section{Compliance with Ethical Standards}

Conflict of Interest Belinda Fu is founder and director of the Mayutica Institute, an independent educational entity. She is also a professional improvisational theater performer at Unexpected Productions (Seattle, Washington). This author received no financial resources or compensation for development of this manuscript from her affiliated institutions. The author has disclosed these interests fully to the editors and has in place an approved plan for managing any potential conflicts arising from these involvements.
Ethical Approval Not applicable

Informed Consent Not applicable

\section{References}

1. Watson K, Fu B. Medical improv: a novel approach to communication and professionalism training. Ann Intern Med. 2016;165: 591-2.

2. Kaplan-Liss E, Lantz-Gefroh V, Bass E, Killebrew D, Ponzio NM, Savi C, et al. Teaching medical students to communicate with empathy and clarity using improvisation. Acad Med. 2018;93(3):440-3.

3. Gao L, Peranson J, Nyhof-Young J, Kapoor E, Rezmovitz J. The role of "improv" in health professional learning: A scoping review. Med Teach. 2018;41:561-8. https://doi.org/10.1080/0142159X. 2018.1505033.

4. Fu B. Common ground: frameworks for teaching improvisational ability in medical education. Teach Learn Med. .

5. Watson K. Perspective: serious play: teaching medical skills with improvisational theater techniques. Acad Med. 2011;86(10):1260-5.

6. Gunderman R. Education in professionalism: improvisation. Acad Radiol. 2016;23(5):655-7.

7. Bynum WE, Goodie JL. Shame, guilt, and the medical learner: ignored connections and why we should care. Med Educ. 2014;48(11):1045-54.

8. Smith, Matt. The Failure Bow. https://www.youtube.com/watch? $\mathrm{v}=\mathrm{cXuD} 2 \mathrm{zHV}$

9. Felsman P, Gunawardena S, Seifert CM. Improv experience promotes divergent thinking, uncertainty tolerance, and affective wellbeing. Think Skills Creat. 2020;35:1871.

10. Hoffman K. Rossing and Weinstein. Twelve tips for using applied improvisation in medical education. Med Teach. 2018;40(4):351-6.

11. Neff KD. The development and validation of a scale to measure self-compassion. Self-Identity. 2003;2:223-50.

12. Hoffman ML. Interaction of affect and cognition in empathy. In: Izard CE, Kagan J, Zajonc RB, editors. Emotions, cognition, and behavior. Cambridge: Cambridge University Press; 1984. p. 103-31.

13. Davis MH, Kraus SJ. Dispositional empathy and social relationships. In: Jones WH, Perlman D, editors. Advances in personal relationships, vol. 3. London: Jessica Kingsley Publishers; 1991. p. $75-115$.

14. Peabody FW. The care of the patient. JAMA. 1927;88:877-82.

15. Brown-Johnson C, Schwartz R, Maitra A, Haverfield MC, Tierney A, Shaw JG, et al. What is clinician presence? a qualitative interview study comparing physician and non-physician insights about practices of human connection. BMJ Open. 2019;9(11):e030831.

16. Ventres WB, Frankel RM. Shared presence in physician-patient communication: a graphic representation. Fam Syst Health. 2015;33(3):270-9.

Publisher's Note Springer Nature remains neutral with regard to jurisdictional claims in published maps and institutional affiliations. 